\title{
Food allergy in Singapore: opening a new chapter
}

\author{
Alison Joanne $\underline{\mathrm{Le}}^{1}$, MBBS, MMed (Paeds), Lynette Pei-Chi Shek ${ }^{1,2}$, MBBS, MRCP
}

ABSTRACT With the exception of shellfish, the overall food allergy rates in Singapore have not reached the epidemic proportions of the West. The rates of egg, milk and fish allergies remain low. However, the patterns of some food allergies in Singapore have changed over the last decade. For example, peanut allergy, once rare in Singapore, is now the most common cause of anaphylaxis in children. Studies analysing lifestyle practices, particularly with respect to prevention of food allergy, are necessary in order for practitioners to understand global differences and maintain this low prevalence.

Keywords: epidemiology, food allergy, peanut, shellfish, Singapore

\section{INTRODUCTION}

Singapore has rapidly evolved into a modernised city state and currently faces the health burden of noncommunicable diseases (NCDs), resembling that of developed Western nations. ${ }^{(1)}$ In children, allergic diseases, including food allergy, are among the most common NCDs. ${ }^{(2)}$ Food allergy rates are reported to be more than $10 \%$ in challenge-proven studies among Australian infants, ${ }^{(3)}$ while in the United Kingdom $(U K)^{(4)}$ and the United States of America (USA), ${ }^{(5)}$ the prevalence rates have doubled in the last decade.

The International Study of Asthma and Allergies in Childhood (ISAAC) data in 2007 demonstrated that the prevalence rates in Singaporean children decreased significantly from $15.7 \%$ to $10.2 \%$ for asthma, and remained largely stable for allergic rhinoconjunctivitis over a seven-year period. ${ }^{(6)}$ These decreasing or stable trends have also been demonstrated in other Asian countries, such as South Korea, Hong Kong and Malaysia, despite urbanisation. ${ }^{(7)}$ Just as these allergic diseases in Singapore have not met the expected rise experienced by other highly industrialised countries, it is also uncertain whether the food allergy epidemic will hit our nation. This unclear prediction, together with ever-changing cultural practices and eating habits due to immigration and overseas influence, has opened a new chapter of food allergy in Singapore.

A PubMed search of the terms "food allergy" and "Singapore" generated a total of 45 results from January 1999 to January 2014. All the articles generated are in English. Of these, 12 articles are not food-allergy focused, and two are focused on food testing methodology that is not unique to Singapore. Of the remaining 31 articles found, 16 are studies conducted on children, and 9 are review articles on food allergy in Asia or Singapore.

\section{EPIDEMIOLOGY}

In Asia, food allergy data is just beginning to emerge, providing no satisfactory trend. One study from Chongqing, China, reported a doubling in the challenge-proven prevalence rates from $3.5 \%$ to $7.7 \%$ among 0 -2-year-olds over a ten-year period. ${ }^{(8)}$ Conversely, a South Korean study reported that the prevalence of food allergy symptoms in 6-12-year-olds had decreased from $10.9 \%$ to $8.9 \%$ over five years. ${ }^{(9)}$ Preliminary findings in an ongoing study of young Singaporean children aged 11-30 months demonstrated that overall, self-reported food allergy prevalence could be as high as $5.4 \%$ (Lee AJ, unpublished). Unfortunately, the only prior data for comparison was in 6-12-year-olds, where the rates (also by questionnaire) were estimated to be $4 \%-5 \%$ in $1999 .{ }^{(10)}$ Given that the prevalence of food allergy tends to decrease with age, using this data, we surmise that food allergy has probably not increased in Singapore over a 14-year period.

\section{SPECIFIC FOOD ALLERGIES IN SINGAPORE}

Worldwide and regional differences in food allergies mainly depend on diet and culture (although this may not always be the case). For example, shellfish is the most common food allergen in Singapore and is ubiquitous in Southeast Asia, likely by virtue of its high consumption. However, fish, also eaten abundantly in Singapore, is a rare allergen here. Allergy to egg and cow's milk, despite their high consumption worldwide, is comparatively lower in Singapore than in the West. The reverse is true of peanut allergy, which is epidemic in the West compared to Asia. However, the pattern of food allergy in Singapore appears to have changed over the last decade, with peanut allergy increasing in prevalence and being the most common cause of anaphylaxis in Singaporean children now. The reasons for these differences and changing patterns are yet to be established. Table I shows the prevalence of specific immunoglobulin E (IgE)-mediated food allergies in Singapore.

\section{Shellfish}

Shellfish is the most common food allergen in Singapore. The prevalence of shellfish allergy in older children is high at

${ }^{1}$ Department of Paediatrics, Khoo Teck Puat-National University Children's Medical Institute, National University Hospital, ${ }^{2}$ Department of Paediatrics, National University of Singapore, Singapore

Correspondence: A/Prof Lynette Pei-Chi Shek, Senior Consultant, Department of Paediatrics, National University Hospital, Level 12, NUHS Tower Block, 1E Kent Ridge Road, Singapore 119228. Iynette_shek@nuhs.edu.sg 
Table I. Prevalence of specific IgE-mediated food allergies in Singapore (convincing history).

\begin{tabular}{llcl}
\hline Allergen & Age group & Prevalence (\%) & Study \\
\hline Shellfish & $4-6 \mathrm{yrs}$ & 1.19 & Shek et al ${ }^{(11)}$ \\
& $14-16 \mathrm{yrs}$ & 5.23 & \\
Peanut & $4-6 \mathrm{yrs}$ & 0.64 & Shek et al ${ }^{(11)}$ \\
& $14-16 \mathrm{yrs}$ & 0.47 & \\
Tree nut & $4-6 \mathrm{yrs}$ & 0.28 & Shek et al ${ }^{(11)}$ \\
& $14-16 \mathrm{yrs}$ & 0.30 & \\
Fish & $14-16 \mathrm{yrs}$ & 0.26 & Connet et $\mathrm{al}^{(12)}$ \\
Egg & $11-30 \mathrm{mths}$ & 1.8 & Lee et al \\
Cow's milk & $11-30 \mathrm{mths}$ & 0.5 & Lee et al ${ }^{*}$ \\
\hline
\end{tabular}

*Preliminary data, 2014, unpublished $(n=2,737)$.

$5.23 \%,{ }^{(11)}$ reflecting a typical pattern in Southeast Asia, which is much higher than that in the West, ${ }^{(13)}$ likely due to the high consumption of shellfish in this region. Shellfish allergy persists into adulthood and is the most common cause of food anaphylaxis in the Singaporean adult population. ${ }^{(14)}$ Clinical management is problematic due to the unpredictability of its reaction, which varies with the species of shellfish, the quantity eaten, the body part affected, and possibly, the preparation method. ${ }^{(15-17)}$ In addition, its abundant use in Asian cooking, together with poor food labelling practices in Singapore, ${ }^{(18)}$ makes accidental ingestion of shellfish difficult to avoid.

\section{Egg and cow's milk}

Egg allergy is the most common among young Singaporean children younger than three years old. In an ongoing study of young Singaporean children aged 11-30 months, preliminary findings based on convincing history in Singapore demonstrate food allergy to be $1.8 \%$ for egg and $0.5 \%$ for cow's milk. Confirmation of symptomatic children with skin prick testing indicates a further drop in egg allergy prevalence to $0.3 \%$ (Lee AJ, unpublished). The food challenge data from this study is still pending. This rate is low compared to the prevalence of food challenge-proven egg allergy in children younger than three years old in the UK (1\%), ${ }^{(19)}$ and among infants in Australia $(8.9 \%)^{(3)}$ and China $(2.5 \%){ }^{(20)}$ However, the prevalence rates in Singapore are comparable to those among children younger than three years old in Taiwan $(0.36 \%$ based on history and skin prick test), ${ }^{(21)}$ and $2-7$-year-olds in Hong Kong $(0.41 \%$ based on history alone).(22)

Not only are the rates of egg and cow's milk allergy in Singapore low on a global scale, but it is also suspected that these food allergies are milder (less anaphylaxis) and possibly get outgrown faster $(50 \%$ and $80 \%$ of children by three years of age for egg and cow's milk allergy, respectively) than in the West. ${ }^{(23)}$ However, a follow-up study delineating the natural history of egg and cow's milk allergy in Singapore is yet to be performed, but when completed, it may have implications for local food allergy practices.

\section{Peanut}

Peanut allergy in Singapore is low at $0.64 \%$ in $4-6$-year-olds and $0.47 \%$ in $14-16$-year-olds. ${ }^{(11)}$ This is similar to that of other Southeast Asian countries, ${ }^{(11)}$ and typically much lower than in Australia $(3.3 \%){ }^{(3)}$ the UK $(1.85 \%)^{(24)}$ and the USA $(1.4 \%)^{(5)}$ However, there is evidence of an increasing prevalence of peanut allergy in Singapore. The shift in peanut sensitisation patterns in atopic children from fourth to second place was the initial signal of this change. ${ }^{(25-27)}$ In a recent study by Liew et al, peanut was found to be the top cause of anaphylaxis in a Singapore paediatric emergency centre, ${ }^{(28)}$ whereas it was an absent cause of food anaphylaxis 14 years ago. ${ }^{(29)}$ It is therefore important for medical professionals to watch for this rise in peanut allergy, as it is a frequent cause of fatal anaphylaxis, particularly in adolescents, and is carried into adulthood, with less than $10 \%$ outgrowing this allergy. ${ }^{(30)}$

\section{Fish}

Asia has one of highest consumption of fish in the world, and Singapore is no exception. ${ }^{(31)}$ Unlike shellfish allergy, the prevalence of fish allergy in Singapore remains low at 0.26\%, despite the high consumption of fish. Comparing with other Southeast Asian countries, our prevalence rate is similar to that of Thailand $\left(0.29 \%\right.$ based on convincing history). ${ }^{(12)}$ The low prevalence in some countries was initially thought to be associated with early introduction of fish to the diet as compared to the West. ${ }^{(32)}$ However, in Connet et al's study, the rate of fish allergy in the Philippines, where fish is similarly introduced to the diet at an early age, was found to be surprisingly high at $2.29 \% .{ }^{(12)}$ In addition, the allergic profile of the Filipino group demonstrated a late-onset-type of fish allergy, unlike in Singapore where fish allergy usually occurs in the first year of life. ${ }^{(33)}$ It was proposed by the authors that this entity in the Philippines could be due to differences in fish preparation methods, with the high availability of dried and salted fish as opposed to cooked fish, possibly promoting immunogenicity. ${ }^{(12)}$

Outside the Southeast Asian region, the prevalence rates of fish allergy in ethnically similar countries are also variable. In Taiwan, the prevalence of fish allergy in 4-18-year-olds was reported to be $1.29 \%$ (convincing history and IgE sensitisation). ${ }^{(21)}$ The prevalence in a Hong Kong cohort of 2-7-year-olds was $0.25 \%$ (doctor diagnosed), ${ }^{(22)}$ while that in China was $0.17 \%-0.21 \%$ among $0-2$-year-olds (challenge proven). ${ }^{(8)}$ However, variance in the population age and methodology makes it difficult to compare the different studies. More challenge-proven food allergy studies with consistent criteria are required in order to establish the prevalence of fish allergy and whether early introduction of fish is indeed a protective factor.

\section{Unique allergies}

Bird's nest allergy is unique to Singapore because of the relatively high consumption of this Chinese delicacy. Although it is no 
longer the most common cause of anaphylaxis unlike in the 1980s, ${ }^{(29,34)}$ bird's nest allergy is still common in Singapore, and can be easily managed and diagnosed based on history alone.

Galacto-oligosaccharide (GOS) is a prebiotic found in most milk formulas in Asia, Europe and the USA. However, GOS allergy is a recently described phenomenon unique to Singapore and its neighbouring Southeast Asian countries. It typically presents in older children and adults with no prior cow's milk allergy, who suddenly develop anaphylaxis (rash and wheeze) after ingesting GOS-containing milk formula or product, ${ }^{(35)}$ and is verified with skin prick and in vitro testing. Clinicians should be aware of the presence of GOS allergy and refer patients to paediatric allergists for confirmation, as more of such cases are emerging.

Anaphylaxis from ingestion of dust mite-contaminated flour has been described in Singapore, where the use of wheat flour in home cooking is not abundant, and thus there is a tendency for it to remain stored for long periods. ${ }^{36,37)}$

\section{ANAPHYLAXIS IN SINGAPORE}

Food is the most common trigger for anaphylaxis, accounting for $63.0 \%$ and $44.8 \%$ of all anaphylactic presentations to the emergency department in Singaporean children and adults, respectively. ${ }^{(14,28)}$ Drugs in children $(30 \%)$ and insect stings in adults $(32 \%)$ are the second most common triggers after food. For children, peanut is the top food trigger (19\%), followed by egg (12\%), shellfish (10\%) and bird's nest (10\%). In adults, shellfish accounts for a vast $66 \%$, followed by tree nuts $(6.7 \%)$, fruit $(6.7 \%)$, bird's nest $(3.3 \%)$, peanut $(3.3 \%)$ and fish $(3.3 \%){ }^{(28)}$ Previously, bird's nest was the most prominent cause of anaphylaxis, ${ }^{(27)}$ but this has changed over the years. Even though food allergy in Singapore is comparatively low, it is not surprising that food-triggered anaphylaxis is common given that shellfish and peanuts are hidden foods ubiquitous in Asian cooking. The high risk of anaphylaxis from shellfish and peanut due to avoidance difficulties is also the most common reason for EpiPen ${ }^{\circledR}$ (adrenaline) prescription. ${ }^{(38)}$ Although mortality from anaphylaxis is low, likely due to easy access to emergency services in Singapore, costs to the government and patients can be reduced. This can be achieved through stricter enforcement of food labelling laws, as well as increased awareness of food allergy management at childcare centres and schools in an increasingly childcare-reliant country.

\section{PREVENTION OF FOOD ALLERGY}

The rates of food allergy in Singapore and Asia are generally lower than in the West, ${ }^{\left({ }^{39)}\right.}$ with the exception of shellfish allergy. Genetics explains this in part; however, children of migrant parents tend to adopt the allergic characteristics profile of their newly adopted country, suggesting a strong environmental influence. ${ }^{(24)}$ These environmental risk factors include alterations in the environmental microbiota (hygiene hypothesis), changes in nutritional patterns and a rich sedentary lifestyle, which possibly influence epigenetic mechanisms pre- or perinatally in a dynamic (epi)genetic-environmental interplay. ${ }^{(40)}$

Prenatally, the consumption of probiotics in pregnancy has some impact on prevention of allergic diseases such as eczema, but evidence for the prevention of food allergy is still lacking. ${ }^{(41)}$ In addition, there is increasing evidence that higher intake of peanut, milk and wheat during pregnancy is associated with reduced allergic diseases, including food allergy in midchildhood. ${ }^{(42)}$ Postnatally, although there is no good evidence to show that breastfeeding is protective for allergies, breast milk is still recommended in high-risk allergic infants because of its immunoprotective properties, as well as its numerous other health benefits for infants. However, there is evidence for the use of hydrolysed formulas in preventing food allergies in infants who cannot be completely breast milk-fed. ${ }^{(43,44)}$ A study from Singapore has shown that consuming probiotics in the first six months of life does not impact allergic outcomes. ${ }^{(45)}$

The timing of introduction of complementary solids in infancy is a persistent source of contention in allergy prevention. It is possible that despite rapid urbanisation in Singapore, maintenance of traditional dietary practices such as early introduction of egg and fish in rice porridge, and peanut in soups may have contributed to the low rates of food allergy. ${ }^{(46)}$ This would be in keeping with current knowledge and theories that early consumption of peanut and egg may prevent food allergy. ${ }^{(24)}$ Another interesting practice observed in Singapore is that many community doctors still advise that egg be introduced by one year of age, or even reintroduced if there is a history of mild egg allergy before the uptake of the measles, mumps and rubella (MMR) vaccine. This is due to the lack of knowledge that MMR is safe in egg-allergic children, even those with anaphylaxis to egg. ${ }^{(47)}$ Nonetheless, in terms of early introduction, it would account for the preliminary finding that $80.5 \%$ of this cohort had been introduced egg of any form by the age of 12 months (Lee AJ, unpublished), and may even have contributed to the low rates of egg allergy in Singapore.

Since 2010, local clinical practice guidelines in the management of food allergy have recommended the introduction of semi-solid foods at 4-6 months, ${ }^{(43)}$ and to avoid delay beyond six months even in high-risk atopic children. However, preliminary findings show that the median age of weaning in Singapore is 6 (range 1-24) months. Many physicians in Singapore still advise weaning at six months in accordance with the guidelines of World Health Organization, whose recommendations also cater to more underdeveloped countries. There is no evidence that delayed weaning beyond six months is protective for allergic diseases and food allergy; ${ }^{(48)}$ however, data from ongoing placebo controlled trials in high-risk cohorts are still pending, and would be needed in order to finalise local guidelines on weaning practices to prevent allergic diseases.

In conclusion, with the exception of shellfish, overall food allergy rates in Singapore continue to be low and non-epidemic, unlike in highly industrialised nations. Peanut is an increasingly common life-threatening allergen, and together with unique 
allergies such as GOS, should always be observed for. More studies analysing weaning and lifestyle practices, particularly with respect to food allergy prevention, are necessary in order to maintain this low prevalence in Singapore.

\section{REFERENCES}

1. World Health Organization. Noncommunicable diseases country profiles 2011 [online]. Available at: http://www.who.int/nmh/countries/en/. Accesed March 2013.

2. Prescott SL, Pawankar R, Allen KJ, et al. A global survey of changing patterns of food allergy burden in children. World Allergy Organ J 2013; $6: 21$.

3. Osborne NJ, Koplin JJ, Martin PE, et al. Prevalence of challenge-proven Ig mediated food allergy using population-based sampling and predetermined challenge criteria in infants. J Allergy Clin Immunol 2011; 127:668-76.e1-2.

4. Venter C, Hasan Arshad S, Grundy J, et al. Time trends in the prevalence of peanut allergy: three cohorts of children from the same geographical location in the UK. Allergy 2010; 65:103-8.

5. Sicherer $\mathrm{SH}$, Muñoz-Furlong A, Godbold JH, Sampson HA. US prevalence of self reported peanut, tree nut, and sesame allergy: 11-year follow-up. J Allergy Clin Immunol 2010; 125:1322-6.

6. Wang XS, Tan TN, Shek LP, et al. The prevalence of asthma and allergies in Singapore; data from two ISAAC surveys seven years apart. Arch Dis Child 2004; 89:423-6.

7. Asher MI, Montefort S, Bjorksten B, et al. Worldwide time trends in the prevalence of symptoms of asthma, allergic rhinoconjunctivitis, and eczema in childhood: ISAAC Phases One and Three repeat multicountry cross-sectional surveys. Lancet 2006; 368:733-43.

8. Hu Y, Chen J, Li H. Comparison of food allergy prevalence among Chinese infants in Chongqing, 2009 versus 1999. Pediatr Int 2010; 52:820-4.

9. Oh JW, Pyun BY, Choung JT, et al. Epidemiological change of atopic dermatitis and food allergy in school-aged children in Korea between 1995 and 2000. J Korean Med Sci 2004; 19:716-23.

10. Hill DJ, Hosking CS, Zhie CY, et al. The frequency of food allergy in Australia and Asia. Environ Toxicol Pharmacol 1997; 4:101-10.

11. Shek LP, Cabrera-Morales EA, Soh SE, et al. A population-based questionnaire survey on the prevalence of peanut, tree nut, and shellfish allergy in 2 Asian populations. J Allergy Clin Immunol 2010; 126:324-31, 31.e1-7.

12. Connett GJ, Gerez I, Cabrera-Morales EA, et al. A population-based study of fish allergy in the Philippines, Singapore and Thailand. Int Arch Allergy Immunol 2012; 159:384-90.

13. Lee AJ, Gerez I, Shek LP, Lee BW. Shellfish allergy- an Asia-Pacific perspective. Asian Pac J Allergy Immunol 2012; 30:3-10

14. Thong BY, Cheng YK, Leong KP, Tang CY, Chng HH. Anaphylaxis in adults referred to a clinical immunology/allergy centre in Singapore. Singapore Med J 2005; 46:529-34.

15. Jirapongsananuruk O, Sripramong C, Pacharn P, et al. Specific allergy to Penaeus monodon (seawater shrimp) or Macrobrachium rosenbergii (freshwater shrimp) in shrimp allergic children. Clin Exp Allergy 2008; 38:1038-47.

16. Rosa S, Prates S, Piedade S, Marta CS, Pinto JR. Are there shrimp allergens exclusive from the cephalothorax? Allergy 2007; 62:85-7.

17. Gerez IF, Llanora G, Yap GC, et al. Clinical characteristics of prawn allergy in an Asian population. J Allergy Clin Immunol 2012; 129(Suppl): AB170.

18. Sivaraj H, Rajakulendran M, Lee BW, Shek LP. Challenges faced by expatriate children with food allergy in an Asian country. Ann Allergy Asthma Immunol 2010; 105:323-4.

19. Venter C, Pereira B, Voigt K, et al. Prevalence and cumulative incidence of food hypersensitivity in the first 3 years of life. Allergy 2008; 63:354-9.

20. Chen J, Hu Y, Allen KJ, Ho MH, Li H. The prevalence of food allergy in infants in Chongqing, China. Pediatr Allergy Immunol 2011; 22:356-60.

21. Wu TC, Tsai TC, Huang CF, et al. Prevalence of food allergy in Taiwan: a questionnaire-based survey. Intern Med J 2012; 42:1310-5.

22. Leung TF, Yung E, Wong YS, Lam CW, Wong GW. Parent-reported adverse food reactions in Hong Kong Chinese pre-schoolers: epidemiology, clinical spectrum and risk factors. Pediatr Allergy Immunol 2009;20:339-46.

23. Venter C, Pereira B, Voigt $K$, et al. Prevalence and cumulative incidence of food hypersensitivity in the first 3 years of life. Allergy 2008; 63:354-9.
24. Du Toit G, Katz Y, Sasieni, et al. Early consumption of peanuts in infancy is associated with a low prevalence of peanut allergy. J Allergy Clin Immunol 2008; 122:984-91.

25. Chiang WC, Kidon M, Liew WK, et al. The changing face of food hypersensitivity in an Asian community. Clin Exp Allergy 2007; 37:1055-61.

26. Khoo J, Shek LP, Khor ES, Wang DY, Lee BW. Pattern of sensitization to common environmental allergens amongst atopic Singapore children in the first 3 years of life. Asian Pac J Allergy Immunol 2001; 19:225-9.

27. Shek LP, Lee BW. Food allergy in children - the Singapore story. Asian Pac J Allergy Immunol 1999; 17:203-6.

28. Liew WK, Chiang WC, Goh AE, et al. Paediatric anaphylaxis in a Singaporean children cohort: changing food allergy triggers over time. Asia Pacific allergy 2013; 3:29-34.

29. Goh DL, Lau YN, Chew FT, Shek LP, Lee BW. Pattern of food-induced anaphylaxis in children of an Asian community. Allergy 1999; 54:84-6.

30. Skripak JM, Wood RA. Peanut and tree nut allergy in childhood. Pediatr Allergy Immunol 2008; 19:368-73.

31. Food and Agriculture Organization of the United Nations, Fisheries and Aquaculture Department. The State of World Fisheries and Agriculture (SOFIA) 2002 [online]. Available at: http://www.fao.org/fishery/ publications/sofia/en. Accessed March 2013.

32. Kull I, Bergstrom A, Lilja G, Pershagen G, Wickman M. Fish consumption during the first year of life and development of allergic diseases during childhood. Allergy 2006; 61:1009-15.

33. Lim DL, Neo KH, Yi FC, et al. Parvalbumin - the major tropical fish allergen. Pediatr Allergy Immunol 2008; 19:399-407.

34. Goh DL, Chew FT, Chua KY, Chay OM, Lee BW. Edible "bird's nest" induced anaphylaxis: an under-recognized entity? J Pediatr 2000; 137:277-9.

35. Chiang WC, Huang CH, Llanora GV, et al. Anaphylaxis to cow's milk formula containing short-chain galacto-oligosaccharide. J Allergy Clin Immunol 2012; 130:1361-7.

36. Tay SY, Tham E, Yeo CT, et al. Anaphylaxis following the ingestion of flour contaminated by house dust mites - a report of two cases from Singapore. Asian Pac J Allergy Immunol 2008; 26:165-70.

37. Yi FC, Chen JY, Chee KK, Chua KY, Lee BW. Dust mite infestation of flour samples. Allergy 2009; 64:1788-9.

38. Tham EH, Tay SY, Lim DL, et al. Epinephrine auto-injector prescriptions as a reflection of the pattern of anaphylaxis in an Asian population. Allergy Asthma Proc 2008; 29:211-5.

39. Lee AJ, Thalayasingam M, Lee BW. Food allergy in Asia: how does it compare? Asia Pac Allergy 2013; 3:3-14.

40. Amarasekera M, Prescott SL, Palmer DJ. Nutrition in early life, immune programming and allergies: the role of epigenetics. Asian Pac J Allergy Immunol 2013; 31:175-82.

41. Bertelsen RJ, Brantsæter AL, Magnus MC, et al. Probiotic milk consumption in pregnancy and infancy and subsequent childhood allergic diseases. J Allergy Clin Immunol 2014; 133:165-71.e1-8.

42. Bunyavanich S, Rifas-Shiman SL, Platts-Mills TA, et al. Peanut, milk, and wheat intake during pregnancy is associated with reduced allergy and asthma in children. J Allergy Clin Immunol 2014 Feb 9. doi: 10.1016/j. jaci.2013.11.040. [Epub ahead of print].

43. Lee BW, Aw MM, Chiang WC, et al. Academy of medicine, SingaporeMinistry of Health clinical practice guidelines: management of food allergy. Singapore Med J 2010; 51:599-607.

44. de Silva D, Panesar SS, Thusu S, et al. The acute and long-term management of food allergy: protocol for a rapid systematic review. Clin Transl Allergy 2013; 3:12.

45. Loo EX, Llanora GV, Lu Q, et al. Supplementation with probiotics in the first 6 months of life did not protect against eczema and allergy in at-risk Asian infants: a 5-year follow-up. Int Arch Allergy Immunol 2014; 163:25-8.

46. Chiang WC, Kidon M, Liew WK, et al. The changing face of food hypersensitivity in an Asian community. Clin Exp Allergy 2007; 37:1055-61.

47. James JM, Burks AW, Roberson PK, Sampson HA. Safe administration of the measles vaccine to children allergic to eggs. N Engl J Med 1995; 332:1262-6.

48. Zutavern A, Brockow I, Schaaf B, et al. Timing of solid food introduction in relation to eczema, asthma, allergic rhinitis, and food and inhalant sensitization at the age of 6 years: results from the prospective birth cohort study LISA. Pediatrics 2008; 121:e44-52. 